\title{
O SELVAGEM CEREBRAL: SOBRE A OBRA DE CLAUDE LÉVI-STRAUSS ${ }^{1}$
}

\author{
Clifford Geertz \\ Tradução: Antonio Maurício Dias da Costa* \\ Revisão da TraduÇÃo: John C. DawSEY ${ }^{* *}$
}

\begin{abstract}
"Hoje, às vezes me pergunto se não fui atraído pela antropologia, de forma inconsciente, pela afinidade estrutural entre as civilizações que são seu objeto e os meus próprios processos mentais. Minha inteligência é neolítica."
\end{abstract}

Claude Lévi-Strauss, Tristes Tropiques

se os selvagens estão presos e nós estamos livres ou se nós estamos presos e eles estão

O que dizer, enfim, sobre os selvagens? livres - no final de tudo isso, ainda não Mesmo agora, depois de três séculos de debate sobre a questão - se eles são nobres, bestiais ou mesmo como você e eu; se raciocinam como nós, se estão mergulhados num misticismo demente ou se possuem as mais altas formas de verdade que nós perdemos com nossa avareza; se seus costumes, do canibalismo à matrilinearidade, são meras alternativas, nem melhores nem piores, aos que adotamos ou rudes precursores, agora ultrapassados, ou, ainda, um ajuntamento de coisas exóticas, passageiras, estranhas, impenetráveis e divertidas para colecionar;

1 GEERTZ, Clifford. The Cerebral Savage: on the work of Claude Lévi-Strauss In: The Interpretation of Cultures. New York: Basic Books, 1973. p. 345-359.

* Doutorando em Antropologia Social da Universidade de São Paulo e membro do Núcleo de Antropologia Urbana/USP.

** Professor Livre-Docente do Departamento de Antropologia da Universidade de São Paulo e Coordenador do Núcleo de Antropologia da Performance e do Drama (Napedra)/USP. sabemos. Para o antropólogo, cuja profissão é estudar outras culturas, o quebra-cabeça está sempre consigo. Sua relação pessoal com seu objeto de estudo é, talvez mais do que para qualquer outro cientista, inevitavelmente problemática. Saiba o que ele pensa que é um selvagem e você terá a chave de seu trabalho. Saiba o que ele pensa que é e você saberá que tipo de coisa ele vai dizer sobre qualquer tribo que ele esteja estudando. Toda etnografia é, em parte, filosofia, e grande parte do restante é confissão.

No caso de Claude Lévi-Strauss, Professor de Antropologia Social do Collège de France e atualmente o centro das atenções - atenções que homens como ele, que passam a vida estudando povos distantes, não usufruem normalmente -, separar os elementos espirituais dos descritivos é particularmente difícil. Por outro lado, nenhum antropólogo foi mais insistente no fato de que a prática de sua

\section{tradução}


profissão consistiu numa busca pessoal, direcionada por uma visão pessoal e dirigida a uma salvação pessoal:

Devo à humanidade tanto quanto ao conhecimento. História, política, o universo social e econômico, o mundo físico, mesmo o céu, tudo me rodeia em círculos concêntricos e posso somente escapar desses círculos no pensamento se atribuo a cada um deles parte do meu ser. Como o seixo que marca a superfície da onda com círculos quando a atravessa, devo me atirar na água se procuro sondar as profundidades.

Por outro lado, nenhum antropólogo reivindicou mais para a etnologia como uma ciência positiva:

O objetivo último das ciências humanas não é constituir o homem, mas dissolvêlo. A importância crítica da etnologia é que ela representa o primeiro passo num processo que inclui outros. A análise etnográfica tenta alcançar invariantes para além da diversidade empírica das sociedades... Este empreendimento inicial abre caminho para outros... que desembocam nas ciências naturais: a reintegração da cultura na natureza e, amplamente, da vida na totalidade das suas condições físico-químicas... Pode-se compreender, portanto, porque encontro na etnologia o princípio de toda a pesquisa.

No trabalho de Lévi-Strauss, as duas faces da antropologia - como um modo de dirigir-se ao mundo e como um método de descobrir relações cientificamente constantes entre os fatos empíricos - são colocadas frente a frente, para forçar um confronto direto entre as duas, em vez de (como é mais comum entre os etnólogos) apartadas, o que evita tal confronto e as tensões internas que isso acarreta. Isso explica tanto o poder quanto o encanto maior de sua obra. Há nela um atrevimento e uma espécie de franqueza imprudente. Mas eis aqui, também, a razão da suspeita mais intra-profissional de que o que é apresentado como Alta Ciência seja, na verdade, um esforço engenhoso, cheio de rodeios, para defender uma posição metafísica, fazer avançar um argumento ideológico e servir a uma causa moral.

Talvez não haja aqui nada terrivelmente errado, mas, como no caso de Marx, é bom se precaver para que uma atitude perante a vida não seja tomada como uma simples descrição dela. Todo homem tem o direito de criar seu próprio selvagem para seus propósitos particulares, o que talvez todo homem faça. Mas demonstrar que tal selvagem construído corresponde aos aborígenes australianos, aos povos tribais africanos ou aos indígenas brasileiros é totalmente outra questão.

As dimensões espirituais do encontro de Lévi-Strauss com seu objeto de estudo e o que o tráfego com os selvagens significou para ele pessoalmente são coisas particularmente fáceis de descobrir, já que ele as registrou, com eloqüência figurada, numa obra que, apesar de estar muito longe de ser um grande livro de antropologia, ou mesmo um que seja especialmente bom, é certamente um dos livros mais bem feitos já escritos por um antropólogo: Tristes 
Tropiques $^{2}$. Seu formato segue o modelo da lenda exemplar da Busca Heróica: a partida precipitada de terras ancestrais, que se tornam familiares, estupidificantes e, de alguma forma imprecisa, ameaçadoras (uma cadeira de filosofia num lycée de província na França de Le Brun); a viagem para outro mundo, mais obscuro, um reino mágico, cheio de surpresas, provas e revelações (as selvas brasileiras dos Caduveo, Bororo, Nambikwara e TupiKawahib); o retorno, resignado e exausto, à existência ordinária ("adeus aos selvagens, então, adeus às viagens") com um conhecimento aprofundado da realidade e uma obrigação de comunicar o que aprendeu para aqueles que, menos aventureiros, permaneceram em casa. $\mathrm{O}$ livro é uma combinação de autobiografia, crônica de viajante, tratado filosófico, relato etnográfico, história colonial e mito profético.

O quê, afinal, aprendi dos mestres que escutei, dos filósofos que li, das sociedades que investiguei e da própria Ciência da qual o Ocidente se orgulha? Simplesmente uma ou duas lições fragmentárias que, se agrupadas do início ao fim, reconstituiriam as meditações de [Buda] ao pé de sua árvore.

A viagem marítima foi rotineira, um prelúdio. Refletindo sobre ela vinte anos mais tarde, Lévi-Strauss compara sua posição àquela dos navegadores clássicos. Eles viajavam em direção a um mundo desconhecido, quase intocado pela humanidade, um Jardim do Éden "livre das

2 Tristes Tropiques (Paris, 1955), traduzido com a ausência de vários capítulos para o inglês por John Russel (New York, 1964).

\section{tradução}

agitações da 'história' por dez ou vinte milênios". Ele estava viajando em direção a um mundo corrompido, o qual esses navegadores (e os colonizadores que os seguiram) destruíram com sua cobiça, sua arrogância cultural e sua fúria pelo progresso. Nada ficou do Jardim terrestre, além dos restos. Sua natureza foi transformada e tornou-se "histórica onde ela havia sido eterna e social onde havia sido metafísica". Antes, o viajante encontrava civilizações radicalmente diferentes da sua esperando por ele no final de sua jornada. Agora ele se depara com imitações empobrecidas do seu mundo, dispostas aqui e ali pelas ruínas de um passado descartado. Não é de surpreender que ele ache o Rio decepcionante. As proporções estão todas erradas. A montanha do Pão de Açúcar é muito pequena, a baía está disposta de forma equívoca, a lua tropical parece descaracterizada ao fundo de barracos e bangalôs. Ele desembarcou como um Colombo tardio para fazer uma descoberta acachapante: "Os trópicos não são tão exóticos quanto são anacrônicos".

Em terra dá-se início à descida às profundezas. O roteiro torna-se denso, fantasmagórico, e chega a um desenlace totalmente imprevisto. Não há índios nas periferias de São Paulo, como lhe havia sido prometido em Paris, justamente pelo chefe da École Normale. Se em 1918 dois terços do Estado era descrito no mapa como "território inexplorado, habitado somente por índios", nem um único nativo indígena restava em 1935, quando, em busca de "uma sociedade humana reduzida à sua expressão básica", ele assumiu seu cargo como professor de sociologia na nova 
universidade local. Os mais próximos estavam a várias centenas de milhas distantes, numa reserva, mas não eram muito satisfatórios. Nem índios verdadeiros, nem selvagens verdadeiros, "eles eram um exemplo perfeito daquela condição social que está se tornando mais difundida na segunda metade do século 20: eles eram 'ex-selvagens', quer dizer, [aqueles] sobre os quais a civilização havia sido abruptamente imposta, e logo que deixaram de ser 'um perigo para a sociedade'; a civilização não lhes devotou mais nenhum interesse". Não obstante, o encontro foi instrutivo, como são todas as iniciações, já que eles o desabusaram da "noção ingênua e poética a respeito do que está reservado para nós, que é comum a todos os iniciantes em antropologia”, e assim o prepararam para se confrontar, mais objetivamente, com os indígenas menos "contaminados" com os quais ele se encontraria mais tarde.

Havia quatro grupos destes, cada um deles um pouco mais distante na floresta, um pouco mais intocado, um pouco mais promissor quanto às possibilidades de uma iluminação final. Os Caduveo, no interior do Paraguai, o intrigaram por suas tatuagens corporais em cujos desenhos elaborados ele acreditou poder ver uma representação formal de sua organização social aborígine, já na época bem decadente. Os Bororo, mais no interior da floresta, estavam um tanto mais intactos. Os seus números haviam sido radicalmente reduzidos por doença e exploração, mas eles ainda viviam segundo o antigo padrão de aldeia e empenhavam-se em manter seu sistema clânico e sua religião. Mais ainda para o interior, a simplicidade dos Nambikwara, evocativa da infância, permitiu que ele encontrasse em sua organização política - de pequenos bandos nômades, constantemente reorganizados, dirigidos por chefes temporários -, a sustentação para a teoria do contrato social de Rousseau. E finalmente, próximo à fronteira boliviana, em "território de Crusoé", a gnose pareceria estar enfim ao alcance na forma dos Tupi-Kawahib, que não só eram intocados, mas, o sonho do cientista, não haviam sido estudados:

Nada é mais excitante para um antropólogo do que a perspectiva de ser o primeiro homem branco a adentrar em uma comunidade nativa... Em minha viagem eu iria reviver a experiência dos viajantes do passado; ao mesmo tempo eu deveria ser confrontado com aquele momento, tão crucial para o pensamento moderno, no qual uma comunidade, que se pensava completa, aperfeiçoada e autosuficiente é levada a descobrir que não é nada disso... A contra-revelação, em suma: a evidência de que ela não está sozinha no mundo, de que ela nada mais é do que parte de um vasto conjunto humano, e que para conhecer-se a si mesma, ela deve primeiramente olhar para a imagem irreconhecível de si naquele espelho do qual uma lasca há muito esquecida deveria emitir para mim somente, o seu primeiro e último reflexo.

Com tão grandes expectativas foi um distinto desapontamento dar-se conta de que estes últimos selvagens, ao invés de 
fornecerem uma visão purificada de primitividade, provaram ser intelectualmente inacessíveis, além do alcance. Lévi-Strauss, literalmente, não conseguia se comunicar com eles:

Eu queria ir ao encalço do "Primitivo" até o seu ponto mais distante. Certamente meu desejo realizou-se no encontro com essas pessoas encantadoras que nenhum homem branco havia visto antes de mim e nenhum veria novamente? Minha viagem havia sido arrebatadora $\mathrm{e}$, ao seu final, eu tinha chegado aos "meus" selvagens. Mas, para a minha infelicidade, eles eram muito selvagens... Lá estavam eles, todos prontos para me ensinar seus costumes e crenças, e eu nada sabia de sua língua. Eles estavam tão próximos de mim como uma imagem vista num espelho. Eu podia tocá-los, mas não entendê-los. Eu tive ao mesmo tempo meu prêmio e minha punição, pois meu erro e o da minha profissão não estavam na crença de que os homens são sempre homens? Que alguns são mais merecedores de nosso interesse e nossa atenção por que há algo espantoso para nós em seus modos... Assim que um povo desta espécie é conhecido ou adivinhado, sua estranheza se esvai, e, aí, poder-se-ia ter ficado em casa. Ou, como no presente caso, se a sua estranheza permanecia intacta, isso em nada me ajudava, já que não tinha nem como começar a estudála. Entre esses dois extremos, quais são os casos equívocos que fornecem a nós [antropólogos] os pretextos por quais vivemos? Quem é, afinal, mais enganado pela inquietude que provocamos no leitor? Nossas considerações devem ser empurradas a uma certa distância se pretendemos torná-las inteligíveis, e no entanto, elas devem ser interrompidas ao meio, já que as pessoas às quais elas causam espanto são muito parecidas com aquelas para as quais os costumes em questão são coisas do dia-a-dia. É o leitor que se ilude por acreditar em nós? Ou os iludidos somos nós, que não temos o direito de estar satisfeitos antes de termos completamente dissolvido aquele resíduo que deu à nossa vaidade seu pretexto?

Ao final de sua Busca lá o esperava, portanto, não uma revelação, mas um enigma. $\mathrm{O}$ antropólogo parece condenado a viajar ou entre homens que ele pode entender precisamente, porque sua própria cultura já os contaminou, cobrindo-os de "sujeira, nossa sujeira, que atiramos no rosto da humanidade", ou entre aqueles que, não havendo sido assim contaminados, são por essa razão em grande parte ininteligíveis para ele. Ele é ou um andarilho entre verdadeiros selvagens (dos quais, de todo modo, sobraram poucos e preciosos casos) cuja alteridade isola sua vida da vida deles, ou um turista nostálgico "apressando-se na busca de uma realidade desaparecida... um arqueólogo do espaço, tentando em vão reconstituir a idéia do exótico com a ajuda de uma partícula aqui, de um fragmento de ruínas ali". Confrontado com homensespelhos que se pode tocar, mas não apreender, e com homens meio arruinados, "pulverizados pelo desenvolvimento da civilização ocidental”, Lévi-Strauss se compara ao indígena lendário que esteve na beira do mundo e lá fez perguntas sobre povos e coisas e se desapontou com o que ouviu. "Eu sou a vítima de uma dupla

\section{tradução}


enfermidade: o que eu vejo é um tormento para mim; o que eu não vejo, uma censura."

Deve o antropólogo se desesperar, portanto? Não haveremos nunca de conhecer os selvagens, afinal? Não, porque há outro caminho para acercar-se de seu mundo além do envolvimento pessoal com ele, qual seja: a construção através das partículas e fragmentos de ruínas que ainda podem ser (ou já foram) coletados de um modelo teórico de sociedade que, embora não correspondendo a nenhuma que possa ser observada na realidade, nos ajudará, todavia, a compreender os fundamentos básicos da existência humana. $\mathrm{E}$ isso é possível porque, a despeito da estranheza superficial dos homens primitivos e de suas sociedades, eles não são, num nível mais profundo, psicológico, nada estranhos. A mente do homem é, no fundo, a mesma em todo lugar: sendo que o que não pode ser alcançado através de uma aproximação, de uma tentativa de entrar corporalmente no mundo de tribos selvagens específicas, pode ser obtido, por outra via, permanecendo-se à distância, pelo desenvolvimento de uma ciência do pensamento geral, fechada, abstrata, e formalista, uma gramática universal do intelecto. Não é pelo assalto direto às fortalezas da vida selvagem, procurando uma penetração fenomenológica de sua vida mental (totalmente impossível) que uma antropologia válida pode ser escrita. Isso poder ser feito pela reconstituição intelectual do contorno daquela vida, abstraindo-a de seus restos "arqueológicos" contaminados, reconstruindo os sistemas conceituais que, nas profundezas abaixo de sua superfície, animavam-na e davam-na forma.
O que uma viagem ao coração das trevas não poderia produzir, uma imersão na lingüística estrutural, na teoria da comunicação, na cibernética e na lógica matemática pode fazer. Da desilusão do romantismo de Tristes Tropiques, irrompeu o cientificismo exultante de outra grande obra de Lévi-Strauss, La Pensée Sawvage (1962)³.

\section{II}

La Pensée Sawvage, em efeito, parte de uma idéia inicialmente apresentada em Tristes Tropiques a respeito dos Caduveo e suas tatuagens sociológicas, qual seja: que a totalidade dos costumes de um povo sempre forma um todo ordenado, um sistema. $\mathrm{O}$ número desses sistemas é limitado. Sociedades humanas, como os seres humanos individualmente, jamais criam a partir de um tecido inteiro, mas simplesmente escolhem certas combinações de um repertório de idéias anteriormente disponíveis para elas. Temas em estoque são infinitamente arranjados e rearranjados em padrões diferentes: expressões variantes de uma estrutura ideacional subjacente, que deveria ser possível, com uma dose adequada de engenhosidade, reconstituir. O trabalho do etnólogo é descrever os padrões de superfície o melhor que puder, para reconstituir as estruturas mais

3 Uma tradução (também não integral) apareceu como The Savage Mind (London, 1966). No entanto, a tradução (piedosamente não atribuída) é diferente da sensível interpretação de Russell de Tristes Tropiques, execrável, e eu tenho, de minha parte, feito minhas próprias versões em inglês, ao invés de citar a partir daquelas. A coleção de ensaios de Lévi-Strauss, Anthropologie Structurale, na qual muitos dos temas de seu mais recente trabalho apareceram em primeiro lugar, foi traduzida como Structural Anthropology (New York, 1963); o seu Le Totémisme Aujourd'hui (Paris, 1962), um tipo de guia prático para La Pensée Sauvage, como Totemism (Boston, 1963).

cadernos de campo ' n. 12 - 2004 
profundas das quais eles são oriundos e classificar aquelas estruturas, uma vez reconstituídas, num esquema analítico semelhante à tabela periódica dos elementos de Mendeleev. Tendo feito isso, "tudo o que resta fazer seria reconhecer aquelas [estruturas] que sociedades [específicas] adotaram realmente". A Antropologia é só aparentemente o estudo de costumes, crenças ou instituições. Fundamentalmente ela é o estudo do pensamento.

Em La Pensée Sawvage essa noção chave - de que o selvagem dispõe de um universo fechado de ferramentas conceituais com o qual precisa se virar para construir quaisquer de suas formas culturais reaparece na roupagem do que Lévi-Strauss chama de "a ciência do concreto". Os selvagens constroem modelos de realidade - do mundo natural, do eu, da sociedade. Mas eles o fazem não como os modernos cientistas, que integram proposições abstratas numa moldura da teoria formal, sacrificando a vivacidade das particularidades percebidas pelo poder explicativo de sistemas conceituais generalizantes, mas sim pela ordenação de particularidades percebidas em totalidades imediatamente inteligíveis. A ciência do concreto arranja realidades diretamente sentidas - as diferenças inequívocas entre cangurus e avestruzes, o avanço e o recuo sazonal das águas das marés, o movimento progressivo do sol e as fases da lua. Assim se produzem modelos estruturais que representam a ordem subjacente da realidade de modo analógico. "O pensamento selvagem estende seu alcance por meio de imagines mundi. Ele produz construções mentais que tornam o mundo inteligível na medida em que se tramam modos de assemelhar-se ao mesmo".

Essa ciência não canônica ("que preferimos chamar de 'primária' em lugar de "primitiva"') estabelece uma filosofia da finitude na prática. Os elementos do mundo conceitual estão dados, préfabricados, poder-se-ia dizer, e o pensar consiste em brincar com esses elementos. A lógica selvagem trabalha como um caleidoscópio cujos fragmentos podem se arranjar numa variedade de padrões, ao mesmo tempo em que permanecem inalterados em quantidade, forma ou cor. O número de padrões produzíveis desse modo pode ser grande se os fragmentos são numerosos e variados o suficiente, mas não infinito. Os padrões consistem na disposição dos fragmentos vis-à-vis uns aos outros (quer dizer, eles são uma função das relações entre fragmentos, e não suas propriedades individuais consideradas separadamente). A extensão de transformações possíveis é estritamente determinada pela construção do caleidoscópio, as leis internas que regem a sua operação. O mesmo também ocorre com o pensamento selvagem. Tanto anedótico como geométrico, ele constrói estruturas coerentes dos "cacos remanescentes do processo histórico ou psicológico".

Esses cacos, os fragmentos do caleidoscópio, são imagens originadas do mito, do ritual, da magia e do conhecimento empírico. (Como, precisamente, eles vieram a ser é um dos pontos sobre os quais LéviStrauss não é muito explícito, referindo-se aos mesmos vagamente como o "resíduo de eventos... vestígios fósseis da história de um indivíduo ou de uma sociedade.") 
Tais imagens são inevitavelmente incorporadas em estruturas maiores - nos mitos, cerimônias, taxonomias folk etc. pois, assim como num caleidoscópio, sempre se vê os fragmentos distribuídos de acordo com algum padrão, mesmo que mal formado ou irregular. Mas, como num caleidoscópio, elas são destacáveis dessas estruturas e arranjáveis em outras, alternativas, de natureza similar. Citando Franz Boas: "pareceria que os mundos mitológicos foram construídos somente para serem novamente despedaçados, e que novos mundos foram construídos dos fragmentos". Lévi-Strauss generaliza essa visão permutacional sobre processos de pensamento para tratar do pensamento selvagem em geral. Tudo consiste, tal como num jogo de cartas, no embaralhamento de imagens distintas (e concretas) - animais totêmicos, cores sagradas, direções de vento, deidades solares ou o que quer que seja - para fins de produzir estruturas simbólicas capazes de formular e comunicar análises objetivas (o que não quer dizer acuradas) dos mundos social e físico.

Consideremos o totemismo. Há muito considerado como uma instituição autônoma, unitária, uma espécie de culto primitivo da natureza a ser explicado por meio de teorias mecânicas de um tipo ou de outro - evolucionista, funcionalista, psicanalítica, utilitária - o totemismo é para Lévi-Strauss somente um caso especial dessa tendência abrangente de construir esquemas conceituais a partir de imagens particulares.

No totemismo, uma lógica paralela é (muito subconscientemente) postulada entre duas séries, uma natural e outra cultural. A ordem das diferenças entre os termos de um lado do paralelo é isomórfica relativamente à ordem das diferenças entre os termos do outro lado. No caso mais simples, as diferenças físicas aparentes entre espécies animais - urso, águia, tartaruga, e assim por diante - são postas em correspondência com as diferenças sociológicas entre grupos sociais - clãs A, B, C etc. Não são as características específicas do urso, da águia e da tartaruga como tais que são críticas - raposa, coelho, e corvo também serviriam -, mas o contraste sensível entre qualquer um de seus pares. É a partir disso que o selvagem representa intelectualmente a si e aos outros a estrutura de seu sistema clânico. Quando ele diz que os membros de seu clã são descendentes do urso, enquanto os seus vizinhos são da águia, ele não está dando vazão a um pouco de biologia rudimentar. Ele está dizendo, de uma maneira metafórica e concreta, que a relação entre seu clã e o de seu vizinho é análoga à relação observada entre essas espécies. Consideradas termo a termo, as crenças totêmicas são simplesmente arbitrárias. A "história" as suscitou e a "história" pode finalmente destruí-las, alterar seu papel ou substituí-las por outras. Mas, vistas como um conjunto ordenado, elas se tornam coerentes, já que são capazes então de representar simbolicamente outro tipo de conjunto similarmente ordenado: clãs aliados, exógamos, patrilineares. A questão é geral. A relação entre uma estrutura simbólica e seu referente, a base de seu significado, é fundamentalmente "lógica", uma coincidência de forma - não afetiva, não histórica, não funcional. $O$ pensamento selvagem é razão congelada e a antropologia 
é, como a música e a matemática, "uma das raras e verdadeiras vocações".

$\mathrm{Ou}$ como a lingüística. Pois, na linguagem, as unidades constituintes fonemas, morfemas, palavras - também são, de um ponto de vista semântico, arbitrárias. Por que os franceses chamam um certo animal de "chien" e os ingleses de " $d o g$ ", ou por que os ingleses formam seus plurais acrescentando "s" e os malaios os formam ao dobrar os radicais? Essas não são questões que os lingüistas - lingüistas estruturais, pelo menos - ainda consideram profícuas para fazer, exceto em termos históricos. Somente quando a língua é ordenada, pelas regras da gramática e da sintaxe, em locuções - seqüências de discurso corporificando proposições - que o significado surge e a comunicação é possível. $\mathrm{Na}$ linguagem, essa ordem, que serve como guia, esse $u r$-sistema de formas em termos dos quais unidades distintas são agrupadas de tal modo a fazer o som virar fala, também é subconsciente. Trata-se de uma estrutura profunda que o lingüista reconstitui a partir das suas manifestações de superfície. Alguém pode tomar consciência de suas categorias gramaticais ao ler tratados de lingüística, assim como alguém pode tomar consciência de suas categorias culturais ao ler tratados de etnologia. Mas, em se tratando de atos, tanto falar como agir são performances espontâneas alimentadas por fontes subterrâneas. Finalmente, e mais importante, o estudo lingüístico (juntamente com a teoria da informação e a lógica formal) também define suas unidades básicas, seus elementos constituintes, não em termos de suas propriedades comuns, mas de suas diferenças, quer dizer, contrastando-as em pares. A oposição binária - aquele abismo dialético entre mais e menos que a tecnologia da computação transformou em língua franca da ciência moderna - compõe a base do pensamento selvagem, bem como da linguagem. E, de fato, é ela que os torna formas essencialmente variantes da mesma coisa: sistemas de comunicação.

Abrindo-se essa porta, tudo é possível. Não somente a lógica das classificações totêmicas, mas de qualquer esquema classificatório - taxonomias de plantas, nomes pessoais, geografias sagradas, cosmologias, estilos de corte de cabelo entre os índios Omaha ou motivos desenhados em roncadores australianos pode, en principe, ser exposta. Isso se dá porque elas sempre se delineiam a partir de uma oposição subjacente de termos emparelhados - alto e baixo, direito e esquerdo, paz e guerra, e assim por diante - que se expressa por imagens concretas, conceitos palpáveis, "além dos quais, por razões intrínsecas, é inútil e impossível ir adiante". Mais ainda, uma vez que alguns desses esquemas ou estruturas são identificados, eles podem ser relacionados entre si - ou seja, reduzidos a uma estrutura mais geral e "mais profunda", que os incorpore. Eles são apresentados como mutuamente deriváveis entre si por operações lógicas - inversão, transposição, substituição: todos os tipos de permutações sistemáticas - tal como se transforma uma sentença em inglês em pontos e hífens do código Morse ou uma expressão matemática em seu complemento mudando todos os sinais. É possível mesmo mover-se entre diferentes níveis da realidade social - a troca de mulheres no 
casamento, a troca de presentes no comércio, a troca de símbolos no ritual ao demonstrar que as estruturas lógicas dessas várias instituições são isomórficas quando consideradas como sistemas de comunicação.

Alguns desses ensaios de "sócio-lógica" são, como a análise do totemismo, persuasivos e esclarecedores até onde conseguem ir. (Visto que qualquer conteúdo metafísico ou aura afetiva que essas crenças possam ter são vigorosamente retirados do foco de análise, na verdade não se consegue ir tão longe.) Outros, como a tentativa de mostrar que totemismo e casta podem ("por meio de uma transformação muito simples") ser reduzidos a expressões variantes da mesma estrutura geral subjacente, são ao menos intrigantes, se não precisamente convincentes. Outros ainda, como as tentativas de mostrar que as formas diferentes pelas quais cavalos, cachorros, pássaros e o gado são nomeados compõem um sistema coerente tridimensional de imagens complementares cruzadas por relações de simetria invertida, são triunfos de auto-paródia. Eles são exercícios de "interpretação profunda" forçados o suficiente para fazer até mesmo um psicanalista enrubescer. Tudo é terrivelmente engenhoso. Se um modelo de sociedade que seja "eterno e universal" pode ser construído a partir dos vestígios das sociedades mortas ou evanescentes um modelo que não reflete nem o tempo, nem o espaço, nem a circunstância, mas (isso do Totemismo) "uma direta expressão da estrutura da mente (e por detrás da mente, provavelmente o cérebro)" - então esse pode ser exatamente o modo de construí-lo.
III

O que Lévi-Strauss produziu para si é uma máquina infernal de cultura. Ela anula a história, reduz o sentimento a uma sombra do intelecto e substitui as mentes particulares de selvagens particulares em selvas particulares pela Mente Selvagem imanente a todos nós. Ela fez com que fosse possível para ele escapar do impasse ao qual sua expedição brasileira o conduziu - proximidade física e distância intelectual - levando-o ao que ele talvez sempre e verdadeiramente tenha querido - proximidade intelectual e distância física. "Eu me mantive contra as novas tendências do pensamento metafísico que estavam então [i.e., em 1934] começando a tomar forma", escreveu em Tristes Tropiques, explicando sua insatisfação com a filosofia acadêmica e sua virada para a antropologia.

Eu achei a fenomenologia inaceitável, na medida em que ela postulava uma continuidade entre experiência e realidade. Que uma envolvia e explicava a outra, eu estava bastante inclinado a concordar, mas eu havia aprendido... que não há continuidade na passagem entre as duas e que para alcançar a realidade devemos, primeiro, repudiar a experiência, mesmo que mais tarde a reintegremos numa síntese objetiva na qual a sentimentalidade não faz parte.

Quanto à tendência de pensamento que se realizaria no existencialismo, isso me parecia ser o exato oposto do pensamento verdadeiro, por conta de sua atitude indulgente para com as ilusões da subjetividade. Promover preocupações 
privadas à categoria dos problemas filosóficos é perigoso... desculpável como um elemento no processo de ensino, mas arriscado ao extremo se isso leva o filósofo a voltar as costas para sua missão. Tal missão (que ele desempenha somente até que a ciência seja forte o suficiente para tomá-la da filosofia) é a de compreender o Ser em sua relação consigo e não em relação ao eu.

A Alta Ciência de La Pensée Sauvage e a Busca Heróica de Tristes Tropiques são, basicamente, "transformações muito simples" uma da outra. Elas são expressões variantes da mesma estrutura profunda subjacente: o racionalismo universal do Iluminismo francês. Apesar de todas as apóstrofes à lingüística estrutural, teoria da informação, lógica formal, cibernética, teoria do jogo e outras doutrinas avançadas, não são as figuras de Saussure, ou Shannon, ou Boole, ou Weiner ou von Neumann os verdadeiros gurus de Lévi-Strauss (tampouco são as de Marx ou Buda, a despeito da invocação ritual de ambos para efeitos dramáticos), mas sim Rousseau.

Rousseau é nosso mestre e nosso irmão... Pois há somente uma maneira de escaparmos da contradição inerente à noção da posição do antropólogo, e tal é pela reformulação, por nossa conta, dos procedimentos intelectuais que permitiram a Rousseau avançar das ruínas deixadas pelo Discours sur l'origine de l'Inegalité para o amplo projeto do Contrato Social, cujo segredo é revelado pelo Emile. É ele quem nos mostrou como, depois de termos destruído toda a ordem existente, podemos ainda descobrir os princípios que nos permitem erigir uma nova ordem em seu lugar.

Enfim, como Rousseau, Lévi-Strauss procura não os homens, com os quais ele não se importa muito, mas o Homem, com quem ele está encantado. Tanto em La Pensée Sauvage como em Tristes Tropiques, é esta a jóia no lótus que ele procura. A "base inabalável da sociedade humana”, na verdade, não é nada social, mas psicológica - trata-se de uma mente racional, universal, eterna e, portanto (na grande tradição do moralismo francês), virtuosa.

Rousseau ("dentre todos os philosophes, o mais próximo de ser um antropólogo”) demonstra o método pelo qual o paradoxo do viajante antropólogo - que chega ou muito tarde para encontrar a selvageria ou muito cedo para apreciá-la - pode afinal ser resolvido. Devemos, como ele, desenvolver a habilidade de penetrar a mente selvagem empregando (e, aqui, munindo Lévi-Strauss com o que ele talvez menos precise, mais uma expressão) o que poder-se-ia chamar de empatia epistemológica. A ponte entre nosso mundo e aquele de nossos sujeitos (extinto, opaco ou simplesmente em frangalhos) não reside na confrontação pessoal - a qual, quando acontece, corrompe tanto a nós quanto a eles. Ela reside num tipo de leitura experimental da mente. Rousseau, "experimentando (consigo mesmo) as formas de pensamento adquiridas alhures ou simplesmente imaginadas" (para fins de demonstrar "que toda mente humana é um locus de experiência virtual onde o que passa pelas

\section{tradução}


mentes dos homens, por mais remoto que seja, pode ser investigado"), foi o primeiro a fazer isso. Não se compreende o pensamento dos selvagens nem pela mera introspecção, nem pela mera observação, mas sim procurando pensar como eles pensam e com os seus materiais. O que se precisa, para além de uma etnografia obsessivamente detalhada, é de uma inteligência neolítica.

As conclusões filosóficas que, para LéviStrauss, seguem esse postulado - que os selvagens somente podem ser compreendidos através da atuação restaurada de seus processos de pensamento com os detritos de suas culturas - redundam, por sua vez, numa versão tecnicamente recondicionada do moralismo rousseauniano.

As formas de pensamento selvagem ("inculto", "não domesticado") são primárias na mentalidade humana. Elas são o que todos nós temos em comum. Os padrões de pensamento civilizado ("domesticado", "domado") da ciência e erudição moderna são produções especializadas de nossa própria sociedade. Eles são secundários, derivados, e, embora não sejam inúteis, são artificiais. Apesar dessas formas primárias de pensamento (e, portanto, os fundamentos da vida social humana) serem "indomadas" como o "amor-perfeito selvagem" - o trocadilho espetacularmente intraduzível que dá o título a La Pensée Sanvage -, elas são essencialmente intelectuais, racionais, lógicas, não emocionais, instintivas ou místicas. O melhor período - mas de nenhum modo perfeito - para o homem foi a era neolítica (i.e., pós-agrícola, préurbana), aquilo que Rousseau (que, ao contrário do estereótipo usualmente criado em torno de sua figura, não era um primitivista) chamou de société naissante. Pois foi então que floresceu essa mentalidade, produzindo, a partir de sua "ciência do concreto", aquelas artes da civilização - agricultura, domesticação de animais, cerâmica, tecelagem, conservação e preparação de alimentos etc. - que ainda fornecem os fundamentos de nossa existência.

Teria sido melhor para o homem que ele tivesse se mantido nesta "região intermediária entre a indolência do estado primitivo e a atividade buscante para a qual somos impelidos por nosso amour propre" em vez de a haver abandonado, por alguma circunstância infeliz, pela ambição irrequieta, o orgulho e egoísmo da civilização mecânica. Mas ele a abandonou. A tarefa da reforma social consiste em fazer que nos voltemos novamente em direção àquele estado intermediário, não nos lançando de volta ao neolítico, mas nos apresentando com lembranças incontestáveis de suas realizações humanas, seu encanto sociológico, de modo a nos conduzir para um futuro racional em que seus ideais - de equilíbrio entre autoestima e simpatia geral - realizar-se-ão de forma ainda mais completa. Uma antropologia cientificamente enriquecida ("legitimando os princípios do pensamento selvagem e restaurando-os aos seus devidos lugares") é o agente apropriado de tal reforma. O progresso em direção à bumanness - aquele desdobramento gradual das mais altas faculdades intelectuais que Rousseau chamava de perfectibilité - foi destruído por paroquialismo cultural, munido com uma ciência imatura. $\mathrm{O}$ universalismo cultural, provido de uma 
ciência plenamente desenvolvida, irá colocá-lo novamente em movimento.

Se a raça [humana] até agora se concentrou em uma, e uma única tarefa - a de construir uma sociedade na qual o Homem possa viver -, então as fontes de vigor utilizadas pelos nossos ancestrais remotos estão presentes também em nós. Todas as apostas ainda estão na mesa, e podemos retirá-las quando quisermos. $\mathrm{O}$ que quer que tenha sido feito, e mal-feito, pode ser iniciado novamente: "A era de ouro [escreveu Rousseau] que a superstição cega deitou às nossas costas ou à nossa frente está em nós". A fraternidade humana adquire um significado palpável quando encontramos a imagem que temos dela confirmada na mais pobre das tribos, e quando essa tribo nos oferece uma experiência que, quando acompanhada de muitas centenas de outras, tem uma lição a nos ensinar .

\section{IV}

Mas talvez mais interessante que essa profissão modernizada de uma fé clássica na "voz perpétua e geral dos homens" (para usar uma frase de Hooker) é saber qual será o destino dessa tentativa de pôr a Majestade Razão de volta em seu trono na roupagem do Selvagem Cerebral no mundo de hoje. A despeito do quanto a cercamos de lógica simbólica, álgebra matricial ou lingüística estrutural, podemos - depois de tudo o que aconteceu desde 1762 - ainda acreditar na soberania do intelecto?

Depois de um século e meio de investigações nas profundezas $\mathrm{da}$ consciência humana, que revelaram interesses ocultos, emoções infantis ou um caos de desejos animais, agora temos uma que ali descobre a pura luz da sabedoria natural que brilha sobre todos igualmente. Sem dúvida, ela será saudada, em alguns lugares, com um grau de acolhimento, para não dizer de alívio. No entanto, surpreende o fato de que essa investigação tenha sido lançada a partir de uma base antropológica. Pois os antropólogos estão sempre sendo tentados - como foi, um dia, o próprio LéviStrauss - a sair das bibliotecas e salas de conferências, onde é difícil lembrar que a mente do homem não é um nenhuma luz seca, em direção "ao campo", onde é impossível esquecer isso. Mesmo não mais havendo muitos "selvagens verdadeiros" no mundo, existe por aí um número suficiente de indivíduos humanos vividamente peculiares para fazer qualquer doutrina do homem que o vê como um portador de verdades imutáveis da razão uma "lógica original" procedendo da "estrutura da mente" - parecer simplesmente excêntrica, uma curiosidade acadêmica.

Que Lévi-Strauss tenha sido capaz de transmutar a paixão romântica de Tristes Tropiques no intelectualismo hipermoderno de La Pensée Sauvage é certamente uma façanha espantosa. Mas permanecem as questões que não se pode deixar de colocar. Essa transmutação é ciência ou alquimia? Essa "transformação muito simples" que produziu uma teoria geral a partir de uma decepção pessoal é algo real ou um passe de mágica? É essa uma demolição genuína dos muros que parecem separar as mentes umas das outras quando se mostra que os muros são apenas estruturas de superfície, ou uma

\section{tradução}


132 Clifford Geertz

evasão disfarçada com alto esmero, necessitada pelo fracasso da tentativa de transpô-los quando foram diretamente encontrados? Está Lévi-Strauss escrevendo, como parece pretender nas páginas confiantes de La Pensée Sauvage, um prolegômeno a toda antropologia futura? $\mathrm{Ou}$ está ele, como qualquer inteligência neolítica desenraizada, desterrada numa reserva, rearranjando os cacos de velhas tradições numa vã tentativa de revivificar uma fé primitiva cuja beleza moral é ainda aparente, mas da qual tanto a relevância quanto a credibilidade há muito se afastaram? 


\section{INSTRUÇÕES PARA COLABORADORES}

1. A revista publicará artigos, traduções e resenhas, originais e inéditos, em Língua Portuguesa, assim como comunicações, informes e entrevistas.

Artigos: Será dada prioridade à publicação dos trabalhos produzidos pelos alunos do Programa Pós-Graduação em Antropologia Social da FFLCH-USP. Está aberta a participação de alunos de outros programas de PósGraduação da USP ou de outras Universidades, assim como de outros profissionais em concordância com as preocupações da Antropologia.

Tradução: Nessa seção procura-se publicar uma tradução por número de revista, de um texto, ensaio ou trabalho relevante, que não esteja disponível na Língua Portuguesa.

Resenhas: Essa seção destina-se a publicar resenhas críticas e informativas de publicações recentes (ou antigas, mas importantes).

Comunicações: O objetivo principal dessa seção será apresentar aos leitores resoluções, documentos e textos informativos produzidos por organizações civis, políticas, religiosas, universidades, associações, imprensa, grupos de estudos, etc., que sejam de interesse do antropólogo enquanto profissional e cidadão. Devem ser enviados para publicação, indicando a fonte e, sempre que possível, com autorização da entidade e/ou organização que produziu o documento.

Entrevistas: Essa seção destina-se a publicar entrevistas com antropólogos ou profissionais que desenvolvam trabalhos de interesse da Antropologia.

Ensaio Fotográfico: Essa seção procura divulgar ensaios fotográficos de pesquisadores desenvolvidos em seus campos de pesquisa.

2. Os originais dos artigos serão submetidos a uma avaliação prévia da Comissão Editorial, que avaliará seu enquadramento dentro da linha editorial de Cadernos de Campo. Se aprovado, será enviado a membros da Consultoria Editorial (profissionais da área) que emitirão pareceres. A partir destes pareceres, a Comissão Editorial julgará a viabilidade de sua publicação, aprovando-os com ou sem modificações, ou não os aprovando.

3. Os artigos devem ser apresentados em duas vias impressas, acompanhados de uma cópia em disquete. $\mathrm{O}$ texto deve ser digitado em páginas tamanho $\mathrm{A} 4$, com a extensão de no máximo 20 páginas (fonte Times New Roman, corpo 12 , espaço 1,5). As resenhas críticas não devem ultrapassar 6 páginas. É imprescindível que os autores mandem o disquete com seu 